\title{
Pengaruh E-Marketing dan E-CRM terhadap Loyalitas Nasabah Menggunakan Internet Banking Bank Syariah Mandiri
}

\author{
The Influence of E-Marketing and E-CRM on Customer Loyalty use \\ Internet Banking at Mandiri Syariah Bank at Pontianak
}

\author{
Ana Fitriana \\ STMIK Pontianak \\ E-mail: afitriana186@gmail.com
}

\begin{abstract}
Abstrak
Untuk semakin meningkatkan layanan kepada nasabah, Bank Syariah Mandiri memanfaatkan teknologi internet yang mempermudah pihak bank melayani nasabah mereka selama 24 jam non stop dengan mengusung BSMnet sebagai internet banking. Kehadiran internet memfasilitasi pihak bank untuk melakukan pemasaran dan pelayanan secara elektronik. BSMnet diharapkan dapat memaksimalkan layanan perbankan Bank Syariah Mandiri kepada nasabah mereka di Pontianak khususnya. Maka tujuan dalam penelitian ini adalah untuk mengetahui pengaruh e-Marketing dan e-CRM pada BSMnet terhadap e-Loyalty nasabah Bank Syariah Mandiri cabang Pontianak, sehingga dalam penelitian ini terdapat tiga variabel, yaitu eMarketing (X1), e-CRM (X2) dan Perilaku Pembelian e-Loyalty (Y). Untuk menjawab tujuan penelitian dilakukan analisa secara eksplanasi-asosiatif dengan uji regresi linier berganda. Penelitian dilakukan terhadap 75 responden nasabah Bank Syariah Mandiri, dimana penarikan sampel dilakukan dengan metode purposive sampling. Hasil analisis uji regresi linier berganda menunjukkan bahwa variabel e-Marketing (X1), e-CRM (X2) berpengaruh positif terhadap eLoyalty nasabah Bank Syariah Mandiri cabang Pontianak baik secara parsial (sendiri-sendiri) maupun simultan (bersama-sama) meskipun perannya belum menunjukkan pengaruh yang tinggi.
\end{abstract}

Kata Kunci - e-Marketing, e-CRM, e-Loyalty

\begin{abstract}
To further improve the services to customers, Syariah Mandiri Bank make uses of the internet technology to simplify the bank services to their customers within 24 hours non-stop with BSMnet supported as internet banking. The present of internet facilitates the bank to do marketing and electronic service. BSMnet is expected to maximize the banking services of Syariah Mandiri Bank to their customers especially in Pontianak. Then the purpose of this study is to figure out the influence of e-marketing and e-CRM in BSMnet to Syariah Mandiri Bank e-loyalty customers branch of Pontianak, then there are 3 variables, namely e-marketing (X1), e-CRM (X2), and behaviour of purchasing e-loyalty (Y). To answer the goals of this study then associative explanatory analysis is conducted with multiple linear regression test. 79 Syariah Mandiri Bank customers become the respondents in this study, where the sampling is done by purposive sampling method. The result of associatve explanatory analysis with multiple linear regression test indicates that e-marketing (X1) and e-CRM (X2) varibles influence positively to e-loyalty of Syariah Mandiri Bank branch of Pontianak both partially or simultaneously although the role has not indicated the high influence.
\end{abstract}

Keywords - e-Marketing, e-CRM, e-Loyalty 


\section{PENDAHULUAN}

Seiring perkembangan teknologi, industri perbankan juga terkena dampaknya, terutama dalam upaya peningkatan pelayanan kepada nasabah. Adapun perkembangan teknologi yang mampu meningkatkan pelayanan terhadap nasabah dimulai dari hadirnya ATM di era-80an, disusul dengan mobile banking dan internet banking, autentikasi multi faktor dalam teknologi perbankan, kartu debit dengan cip, dan $e$-wallet. Bagaimanapun juga teknologi telah mengambil peranan besar di segala aspek kehidupan manusia. Dari cara bekerja, hingga cara menghabiskan waktu untuk bersenang senang, teknologi telah mengubah segalanya, termasuk cara manusia untuk melakukan aktivitas perbankan mereka.

Bank Syariah menurut Undang-Undang Republik Indonesia No. 21 Tahun 2008 adalah Bank Syariah adalah Bank yang menjalankan kegiatan usahanya berdasarkan prinsip syariah dan menurut jenisnya terdiri atas Bank Umum Syariah dan Bank Pembiayaan Rakyat Syariah [1]. Prinsip utama lembaga keuangan syariah adalah bebas bunga yang tercermin dalam produkproduk yang dihasilkannya memiliki berbagai pertimbangan dalam memilih usaha jasa perbankan yang akan digunakannya, hal tersebut dapat dilihat dari faktor tingkat pelayanan, tingkat bunga yang ditawarkan, tingkat kenyamanan yang dirasakan oleh masyarakat dalam hal penyimpanan uang pada bank tersebut, juga mengenai kemudahan dalam memperoleh pinjaman. Faktor-faktor tersebut yang menjadi dasar pertimbangan masyarakat untuk memilih jasa perbankan, baik secara langsung maupun tidak langsung dapat membentuk loyalitas pada diri masyarakat akan bank yang dijadikan sebagai pilihan yang dipercayainya.

Untuk semakin meningkatkan layanan kepada nasabah, Bank Syariah Mandiri memanfaatkan teknologi internet yang mempermudah pihak bank melayani nasabah mereka selama 24 jam non stop. Kehadiran internet memfasilitasi pihak bank untuk melakukan pemasaran dan pelayanan secara elektronik. Dimana transaksi perbankan konvensional seperti cek saldo, transfer, pembayaran PLN, PDAM, tv kabel, isi ulang pulsa, informasi kurs, info harga emas, dan beragam transaksi belanja online dapat dilakukan secara fleksibel 24 jam nonstop oleh nasabah melalui intenet banking, karena nasabah bisa mengakses intenet banking kapan saja dan dimana saja. Baik bank pemerintah maupun swasta saat ini sudah memfasilitasi nasabahnya dengan fitur intenet banking, hal ini tentu saja sejalan dengan salah satu tujuan utama setiap bank yaitu memberikan pelayanan terbaik bagi nasabah sehingga mampu membuat mereka loyal terhadap bank tersebut. Sama halnya dengan yang dilakukan Bank Syariah Mandiri yang mengusung BSMNet sebagai intenet banking bagi nasabah mereka. Dalam upaya mencapai loyalitas nasabah mereka melengkapi BSMNet dengan beragam fitur yang memudahkan transaksi internet banking, update info perbankan secara harian, info kurs, harga emas, tips aman bertransaksi, pengaduan nasabah, sampai fitur edukasi syariah yang dapat menambah wawasan nasabah tentang Islam. Fitur terakhir ini sejalan dengan prinsip bank syariah mandiri yaitu, tampil dan tumbuh sebagai bank yang mampu memadukan idealisme usaha dengan nilai-nilai rohani, yang melandasi kegiatan operasionalnya. Harmoni antara idealisme dan nilai-nilai rohani inilah yang menjadi salah satu keunggulan Bank Syariah Mandiri dalam kiprahnya di perbankan Indonesia yang kemudian dibuktikan dengan melibatkan fitur edukasi syariah bagi pengguna BSMnet. Diharapkan kehadiran BSMnet mampu memberikan nilai lebih bagi nasabah, sehingga loyalitas nasabah bisa tercapai.

Dari hasil penelitian terhadap variabel-variabel yang dilibatkan dalam penelitian ini yang pernah diteliti sebelumnya diperoleh hasi sebagai berikut, dalam penelitian investigasi perbandingan, dampak dari strategi keunggulan bersaing dalam e-marketing terhadap e-loyalty dengan menggunakan model Porter menghasilkan bahwa variabel dalam model Porter berpengaruh positif terhadap e-loyalty konsumen terutama faktor keunggulan biaya sangat berpengaruh terhadap kepuasan konsumen [2]. Kemudian dalam penelitian sejenis lainnya menunjukkan bahwa penerapan e-CRM oleh bank dapat membantu perusahaan meningkatkan kepuasan konsumen, dimana kepuasan konsumen adalah salah satu faktor utama penentu loyalitas [3]. Adapun penelitian tentang e-loyalty terhadap website komunikasi pemasaran diketahui bahwa beberapa faktor yang harus diperhatikan perusahaan mengenai variabel terkait adalah sebagian 
besar pengguna merasa informasi yang tersedia pada website tidak seluruhnya dapat digunakan pada saat masa akses dan URL (alamat) website sulit untuk diingat dan kesediaan untuk mengunjungi website kembali mendapatkan nilai paling rendah diantara seluruh faktor yang diteliti [4].

Terdapat beberapa perbedaan antara penelitian yang dilakukan saat ini dibandingkan dengan penelitian-penelitian terdahulu. Misalnya pada penelitian perbandingan strategi keunggulan bersaing Porter dalam $e$-marketing terhadap $e$-loyalty variabel yang diteliti tidak ada variebel e-CRM, dan pada e-CRM mobile banking variabel yang diteliti tidak ada variabel eMarketing, sedangkan pada penelitian terhadap website komunikasi pemasaran variabel yang dilibatkan sama hanya saja jenis website yang diteliti berbeda yaitu non-ecommerce. Oleh karena itu peneliti tertarik untuk meneliti pengaruh variabel e-Marketing dan e-CRM secara bersamasama terhadap loyalitas nasabah menggunakan intenet banking Bank Syariah Mandiri.

\section{METODE PENELITIAN}

Variabel bebas yang dibahas dalam penelitian ini terdiri dari e-marketing dan e-customer relationship management (e-CRM). Sedangkan variabel terikatnya adalah loyalitas nasabah. EMarketing adalah penggunaan teknologi informasi dalam proses membuat, mengkomunikasikan, dan menyampaikan nilai (value) kepada pelanggan, dan dapat juga digunakan untuk menjaga hubungan pelanggan demi keuntungan bersama. Perusahaan perlu mempertimbangkan peluang pemasaran elektronik; oleh karena itu perusahaan perlu mengetahui bagaimana menciptakan sebuah situs web yang menarik [5]. Oleh karena itu website yang menjadi sarana e-marketing haruslah memiliki kualitas yang baik dan memuaskan pengguna untuk dapat menghasilkan loyalitas. Dalam penelitian ini terdapat tiga kriteria untuk mengukur website yang menjadi sarana e-marketing yaitu accessibility (tingkat kemampuan akses sebuah website), currency/timeliness yang berhubungan dengan berbagai update yang tersedia di website, dan accuracy/cridibility adalah seberapa factual dan verifiable informasi dan materi yang disediakan website [6]. Penggunaan 3 kriteria tersebut pada penelitian ini dirasa sangat cocok untuk meneliti website BSMnet yang juga digunakan sebagai media e-Marketing Bank Syariah Mandiri.

Jika e-marketing adalah proses penyampaian nilai kepada pelanggan, e-CRM adalah sistem yang digunakan untuk mempertahankan nilai yang tersampaikan tersebut. $E$-CRM adalah sebuah manajemen hubungan pelanggan yang diadakan secara elektronik [7]. E-CRM adalah penggunaan teknologi komunikasi digital untuk memaksimalkan hubungan bisnis dengan pelanggan yang ada dan terus mendorong penggunakaan layanan online [8]. Berdasarkan pengertian tersebut diharapkan keberadaan e-CRM pada website perusahaan dapat menghasilkan penggunaan website yang berkelanjutan (e-Loyalty). Implementasi $e$-CRM dapat diharapkan untuk menghasilkan nilai yang signifikan bagi perusahaan dan pelanggan pada zaman ketika masyarakat terhubung satu sama lain [9]. Oleh karena itu, dengan jumlah pengguna internet yang terus meningkat hal ini dibuktikan dengan pengguna internet Indonesia nomor enam dunia [10], maka e- CRM adalah solusi yang tepat bagi perusahaan dalam mempertahankan hubungan pelanggan. Dalam penelitian ini e-CRM diukur dengan 3 dimensi yaitu, information quality, customer service efficency, dan ease of navigation [11].

E-loyalty adalah perluasan konsep loyalitas konvensional yang diterapkan secara online [12]. E-loyalty adalah niatan untuk mengunjungi website kembali dengan atau tanpa terjadinya transaksi online. Dalam penelitian ini e-loyalty diukur dengan menggunakan 3 indikator yaitu, cognitive, affective, dan conative, dengan masing-masing indikatornya adalah preference, positive attitudes, revisit, dan retransaction [13].

Skala pengukuran yang digunakan pada penelitian ini adalah: Untuk mengukur $e$ marketing dan e-customer relationship management (e-CRM) menggunakan skala Likert berskala 5 dengan skor: sangat setuju $=5$, setuju $=4$, kurang setuju $=3$, tidak setuju $=2$, sangat tidak setuju $=1$. Kemudian data dianalisis dengan menggunakan SPSS Regresi Berganda (Multiple Regression) guna mengetahui besarnya pengaruh e-marketing dan e-customer 
relationship management (e-CRM) baik secara simultan maupun parsial terhadap loyalitas nasabah mengunjungi BSMnet. Adapun rumus Regresi Berganda (Multiple Regression) adalah sebagai berikut [14]:

dimana:

$$
Y=a+b_{1} X_{1}+b_{2} X_{2}+e
$$

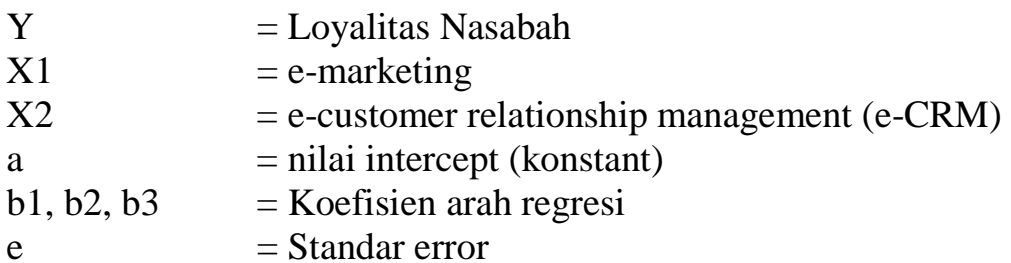

Jenis penelitian yang digunakan untuk menganalisis data adalah eksplanasi-asosiatif dengan metode penelitian survei melalui penyebaran kuesioner. Unit analisis adalah nasabah pengguna BSMnet di Pontianak. Penelitian eksplanasi yaitu penggunaan data yang tersedia untuk menjelaskan hubungan kausal antara variabel melalui pengujian hipotesis; sedangkan asosiatif adalah penelitian eksplanasi yang menguji hubungan antara dua variabel atau lebih [14]. Metode survei digunakan untuk mengumpulkan data berupa pernyataan yang kemudian akan diubah menjadi data kuantitatif dengan skala Likert.

Pada penelitian ini e-marketing dan e-customer relationship management (e-CRM) diduga berpengaruh secara langsung pada loyalitas nasabah menggunakan internet banking BSMnet. Faktor-faktor lainnya yang dapat mempengaruhi loyalitas nasabah menggunakan internet banking tidak dibahas pada penelitian ini. Pada kerangka pemikiran berikut digambarkan bentuk hubungan antara variabel bebas dan variabel terikat yang dibahas pada penelitian ini. Supaya dengan mudah diketahui faktor-faktor apa saja yang diteliti. Seperti yang ditampilkan pada gambar 1 berikut:

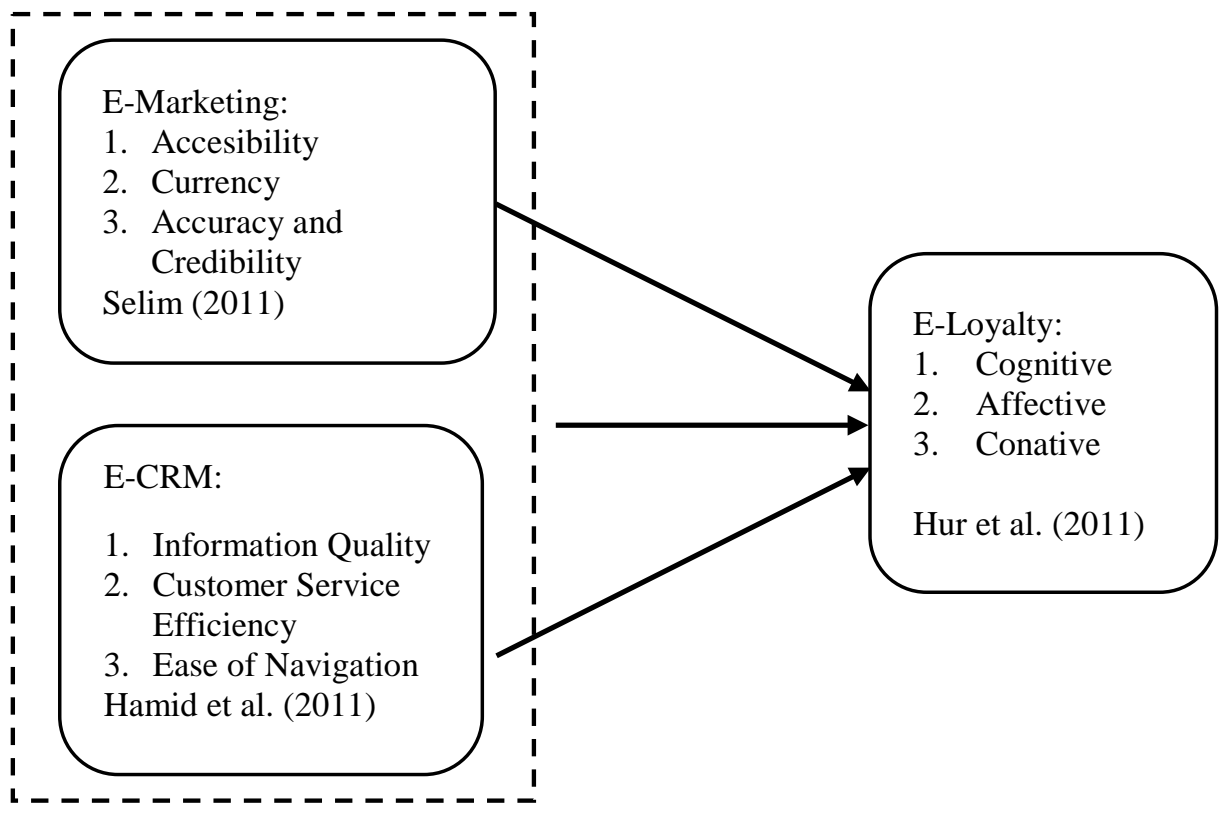

Gambar 1. Kerangka Pemikiran 
Berdasarkan kerangka pemikiran, berikut ini adalah hipotesis yang akan diuji pada penelitian ini:

$\mathrm{T}-1$

$\mathrm{H}_{0} \quad$ : E-marketing tidak memiliki hubungan dan pengaruh terhadap loyalitas nasabah Bank Syariah Mandiri cabang Pontianak menggunakan internet banking

$\mathrm{H}_{1} \quad$ : E-marketing memiliki hubungan dan pengaruh terhadap loyalitas nasabah Bank Syariah Mandiri cabang Pontianak menggunakan internet banking

$\mathrm{T}-2$

$\mathrm{H}_{0} \quad$ : E-CRM tidak memiliki hubungan dan pengaruh terhadap loyalitas nasabah Bank Syariah Mandiri cabang Pontianak menggunakan internet banking

$\mathrm{H}_{1} \quad$ : E-CRM memiliki hubungan dan pengaruh terhadap loyalitas nasabah Bank Syariah Mandiri cabang Pontianak menggunakan internet banking

$\mathrm{T}-3$

$\mathrm{H}_{0} \quad$ : E-marketing dan E-CRM tidak memiliki hubungan dan pengaruh terhadap loyalitas nasabah Bank Syariah Mandiri cabang Pontianak menggunakan internet banking

$\mathrm{H}_{1} \quad$ : E-marketing dan E-CRM memiliki hubungan dan pengaruh terhadap loyalitas nasabah Bank Syariah Mandiri cabang Pontianak menggunakan internet banking

Penarikan kesimpulan untuk hipotesis di atas didasarkan pada perbandingan nilai t hitung terhadap t tabel, dengan syarat:

Jika nilai t hitung > t tabel, maka $\mathrm{H} 1$ diterima dan $\mathrm{H} 0$ ditolak

JIka nilai t hitung $<\mathrm{t}$ tabel, maka H0 diterima dan H1 ditolak

Adapun operasionalisasi variabel yang bekerja dalam penelitian ini ditujukan dalam Tabel 1.

Tabel 1. Operasionalisasi Variabel

\begin{tabular}{|l|l|l|l|}
\hline Variabel & Dimensi & Indikator & Skala Pengukuran \\
\hline $\begin{array}{l}\text { E-Marketing } \\
\text { (Selim, 2011) }\end{array}$ & Accessibility & $\begin{array}{l}\text { - Searchable } \\
\text { - Efficiency } \\
\text { - Compatibility } \\
\text { - Updates } \\
\text { - Timeliness } \\
\text { - Factual } \\
\text { - Verifiable }\end{array}$ & Likert \\
& Accuracy and Credibility & Likert \\
\hline $\begin{array}{l}\text { E-CRM } \\
\text { Hamid et al. (2011) }\end{array}$ & Information Quality & $\begin{array}{l}\text { - Relevancy } \\
\text { - Sufficiency } \\
\text { - Understandability }\end{array}$ & Likert \\
& Customer service & $\begin{array}{l}\text { - Careful } \\
\text { - Continous } \\
\text { - Content layout }\end{array}$ & Likert \\
& Ease of navigation & - Easeofuse & Likert \\
\hline $\begin{array}{l}\text { E-Loyalty } \\
\text { (Hur et al., 2011) }\end{array}$ & $\begin{array}{l}\text { Cognitive } \\
\text { Affective } \\
\text { Conative }\end{array}$ & $\begin{array}{l}\text { - Preference } \\
\text { - Positive attitudes } \\
\text { - Revisit } \\
\text { - Retransaction }\end{array}$ & $\begin{array}{l}\text { Likert } \\
\text { Likert } \\
\text { Likert } \\
\text { Likert }\end{array}$ \\
\hline
\end{tabular}

Populasi dalam penelitian ini adalah nasabah Bank Syariah Mandiri di Pontianak. Dalam penelitian ini, jumlah populasi nya tidak diketahui dikarenakan pihak bank sangat menjaga kerahasiaan data nasabah. Sehingga penentuan ukuran sampel dari populasi yang tidak diketahui menggunakan acuan penentuan jumlah sampel menurut Roscoe yang dikutip Uma Sekaran, dimana dalam penelitian multivariate (termasuk analisis regresi berganda) ukuran sampel sebaiknya sepuluh kali lebih besar dari jumlah variabel dalam penelitian [14]. Berdasarkan acuan 
tersebut, sampel yang dilibatkan dalam penelitian ini adalah sebanyak 75 orang. Dengan pertimbangan jumlah yang memenuhi acuan tersebut di atas dan kemudahan menjumpai pengguna BSMnet di Pontianak minimal tiga bulan terakhir. Adapun penarikan sampel yang digunakan dalam penelitian ini adalah teknik purposive sampling, dalam teknik ini pemilihan unit sampling dilakukan dengan mempertimbangkan syarat-syarat yang telah ditetapkan sebelumnya [14].

\section{HASIL DAN PEMBAHASAN}

Sebelum data diproses regresi lebih lanjut, data sudah melewati pengujian validitas dan reliabilitas serta uji asumsi klasik. Dan hasilnya adalah data valid, reliabel dan terbebas dari gejala multikolinieritas, data terdistribusi normal, terbebas dari gejala autokorelasi, dan memenuhi standar heterokedastisitas.

Untuk mengetahui terjadi atau tidaknya multikolinieritas dapat dilihat dari menyatakan bahwa nilai Variance Inflating Factor (VIF) di bawah 10 maka tidak terjadi multikolinieritas [15]. Kemudian untuk melihat data terdistribusi normal atau tidak bisa menggunakan grafik distribusi histogram dan normal P-P Plot of Regression Standardized Residual. Sedangkan untuk mendeteksi gejala autokorelasi menggunakan uji Durbin-Watson (DW), untuk mengetahui uji heterokedastisitas adalah dengan melihat penyebaran dari varians residual dengan melihat Scatterplot.

Adapun hasil perhitungan regresi bergandanya dapat dilihat dari Tabel 2 berikut:

Tabel 2. Hasil Uji Regresi Linier Berganda secara Parsial

(Sumber: Data primer diolah (2018))

\begin{tabular}{|c|c|c|c|c|c|c|c|c|c|c|c|}
\hline \multicolumn{12}{|c|}{ Coefficients $^{\mathrm{a}}$} \\
\hline \multirow{2}{*}{\multicolumn{2}{|c|}{ Model }} & \multicolumn{2}{|c|}{$\begin{array}{c}\text { Unstandardized } \\
\text { Coefficients } \\
\end{array}$} & \multirow{2}{*}{$\begin{array}{c}\text { Standardized } \\
\text { Coefficients } \\
\text { Beta }\end{array}$} & \multirow[b]{2}{*}{$\mathrm{t}$} & \multirow[b]{2}{*}{ Sig. } & \multicolumn{3}{|c|}{ Correlations } & \multicolumn{2}{|c|}{ Collinearity Statistics } \\
\hline & & B & Error & & & & Zero-order & Partial & Part & Tolerance & VIF \\
\hline \multirow[t]{3}{*}{1} & (Constant) & 1.544 & .656 & & 2.406 & .000 & & & & & \\
\hline & PU & .110 & .142 & .089 & 1.769 & .444 & .082 & .290 & .089 & .998 & 1.002 \\
\hline & PEU & .209 & .146 & .166 & 1.833 & .156 & .162 & .467 & .166 & .998 & 1.002 \\
\hline
\end{tabular}

Dari hasil perhitungan yang ditunjukkan pada Tabel 2 di atas, diperoleh persamaan regresi sebagai berikut:

$$
Y=1,544+0,110 X_{1}+0,209 X_{2}+e
$$

a. Pengaruh e-Marketing (X1) terhadap e-Loyalty (Y)

Berdasarkan persamaan regresi dan tabel output uji t (Tabel 2), pengaruh variabel eMarketing (X1) terhadap e-Loyalty (Y) dapat disimpulkan bahwa:

Tabel 3. Pengaruh e-Marketing terhadap e-Loyalty (Sumber: Data primer diolah (2018))

\begin{tabular}{|c|c|c|c|}
\hline$\beta$ & $\mathbf{t}_{\text {hitung }}$ & $\mathbf{t}_{\text {tabel }}$ & Korelasi Parsial \\
\hline 0,110 & 1,769 & 1,666 & 0,290 \\
\hline
\end{tabular}


Berdasarkan Tabel 3 di atas dapat diambil beberapa kesimpulan sebagai berikut nilai $t_{\text {hitung }} 1,769$ lebih besar dari $t_{\text {tabel }}$ untuk $\alpha=0,05 \%$ dan derajat bebas $=72$ sebesar 1,666, sehingga dapat diambil keputusan menerima $\mathrm{H}_{1}$ danmenolak $\mathrm{H}_{0}$, hal ini berarti berdasarkan hasil penelitian terdapat pengaruh yang signifikan dari variabel $e$-Marketing terhadap $e$-Loyalty. Sehingga jika nilai variabel $e$-Marketing naik sebesar 1 satuan, maka nilai variabel $e$-Loyalty akan meningkat pula sebesar 0,110 dengan asumsi variabel independen lainnya konstan. Nilai korelasi parsial sebesar 0,290 menunjukkan keeratan hubungan e-Marketing terhadap e-Loyalty. Diperoleh besarnya pengaruh parsial e-Marketing terhadap e-Loyalty adalah $(0,290) 2 \times 100 \%=$ $8,41 \%$. Hal ini menunjukkan bahwa BSMnet terbilang relatif berhasil memanfaatkan perkembangan teknologi untuk menyampaikan informasi produk-produk Bank Syariah Mandiri kepada pelanggan melalui fitur-fitur yang disediakan di internet banking BSMnet.

\section{b. Pengaruh e-CRM (X2) terhadap e-Loyalty (Y)}

Berdasarkan persamaan regresi dan tabel output uji t (Tabel 2), pengaruh variabel e-CRM (X2) terhadap e-Loyalty (Y) dapat disimpulkan bahwa:

Tabel 4. Pengaruh gender wanita terhadap perilaku pembelian impulsive Sumber: Data primer diolah (2018)

\begin{tabular}{|c|c|c|c|}
\hline$\beta$ & $\mathbf{t}_{\text {hitung }}$ & $\mathbf{t}_{\text {tabel }}$ & Korelasi Parsial \\
\hline 0,209 & 1,833 & 1,661 & 0,467 \\
\hline
\end{tabular}

Berdasarkan Tabel 4 di atas dapat diambil beberapa kesimpulan sebagai berikut nilai $t_{\text {hitung }} 1,833$ lebih besar dari $t_{\text {tabel }}$ untuk $\alpha=0,05 \%$ dan derajat bebas $=72$ sebesar 1,666, sehingga dapat diambil keputusan menerima $\mathrm{H}_{1}$ danmenolak $\mathrm{H}_{0}$, hal ini berarti berdasarkan hasil penelitian terdapat pengaruh yang signifikan dari variabel $e$-CRM terhadap $e$-Loyalty. Sehingga jika nilai variabel $e$-CRM naik sebesar 1 satuan, maka nilai variabel $e$-Loyalty akan meningkat pula sebesar 0,209 dengan asumsi variabel independen lainnya konstan. Nilai korelasi parsial sebesar 0,467 menunjukkan keeratan hubungan e-CRM terhadap e-Loyalty. Diperoleh besarnya pengaruh parsial $e$-CRM terhadap $e$-Loyalty adalah $(0,467) 2 \times 100 \%=21,8 \%$. Implementasi $e$ $C R M$ pada Bank Syariah Mandiri berupa penggunaan internet banking yang dimanfaatkan selain untuk memasarkan produk dan melakukan transaksi perbankan secara online, juga menyediakan informasi tentang edukasi syariah yang dapat menambah wawasan agama Islam bagi nasabah. Dimana hal ini dapat menarik nasabah untuk mengunjungi BSMnet kembali tidak hanya sekadar mencari informasi dan melakukan transaksi produk perbankan Bank Syariah Mandiri. Hal ini sejalan dengan hasil penelitian perancangan $e$-CRM pada Bank Internasional Indonesia cabang Pontianak, dimana hasilnya berupa rancangan aplikasi $e$-CRM yang dapat memberikan pelayanan terbaik bagi nasabah Bank BII cabang Pontianak, menampung keluhan yang disampaikan oleh nasabah, dan mengelola hubungan dengan nasabah [16]. Meskipun saat ini perannya belum maksimal. Oleh karena itu tingkat pengaruhnya belum menunjukkan signifikansi pengaruh yang tinggi terhadap $e$-Loyalty.

\section{c. Pengaruh e-Marketing (X1) dan e-CRM (X2) terhadap e-Loyalty (Y) secara simultan}

Pengujian hipotesis ini berguna untuk mengetahui pengaruh yang signifikan secara bersama-sama atau keseluruhan (simultan) antara variabel bebas yang meliputi variabel $e$ Marketing (X1) dan $e$-CRM (X2) terhadap variabel terikat $e$-Loyalty (Y). Dari perhitungan yang telah dilakukan, diperoleh hasil pengujian korelasi berganda secara simultan sebagai berikut: 
Citec Journal, Vol. 4, No. 4, Agustus 2017 - Oktober 2017

Tabel 5. Hasil Pengujian Regresi Berganda secara Simultan

Sumber: Data primer diolah (2018)

\begin{tabular}{|c|c|c|c|c|c|}
\hline $\begin{array}{c}\text { Dependent } \\
\text { Variable }\end{array}$ & $\begin{array}{c}\text { Independent } \\
\text { Variable }\end{array}$ & R Square & F-hit & F-Tabel & Signifikasi \\
\hline $\mathrm{Y}$ & $\mathrm{X}_{1}, \mathrm{X}_{2}$ & 0.407 & 4.41 & 3.12 & $0,000^{\mathrm{a}}$ \\
\hline
\end{tabular}

Berdasarkan Tabel 5 di atas, F-hitung sebesar 4,41 dan F-tabel pada taraf nyata $\alpha=0,05$ sebesar 3,12. Oleh karena F-hitung lebih besar dari F-tabel, atau dapat juga dilihat dari nilai probabilitas sebesar $0,000^{\mathrm{a}}$ yang berada di bawah $\alpha=0,05$, maka dapat disimpulkan bahwa Ho ditolak dan Ha diterima sehingga dapat diartikan bahwa variabel $e$-Marketing (X1) dan e-CRM (X2) berpengaruh positif secara signifikan terhadap e-Loyalty (Y).

Sedangkan besarnya pengaruh secara bersama-sama antara variabel $e$-Marketing (X1) dan $e$-CRM (X2) terhadap e-Loyalty (Y) berpengaruh secara signifikan ditunjukkan oleh nilai adjusted $\mathrm{R}^{2}$ sebesar 0,407 . Artinya $40,7 \%$ munculnya minat nasabah mengunjungi BSMnet kembali dan melakukan transaksi perbankan pada BSMnet disebabkan adanya e-Marketing (X1) dan $e-C R M(\mathrm{X} 2)$ yang diterapkan secara bersama-sama pada BSMnet, sedangkan sisanya 59,3\% merupakan pengaruh faktor lain yang tidak diteliti dalam penelitian ini.

\section{KESIMPULAN}

Berdasarkan hasil pengujian tersebut, maka tujuan penelitian ini dinyatakan tercapai dengan hasil pengujian hipotesis yang menyatakan:

T-1 : E-marketing memiliki hubungan dan pengaruh terhadap loyalitas nasabah menggunakan intenet banking Bank Syariah Mandiri cabang Pontianak

T-2 : E-CRM memiliki hubungan dan pengaruh terhadap loyalitas nasabah menggunakan intenet banking Bank Syariah Mandiri cabang Pontianak

T-3 : E-marketing dan E-CRM memiliki hubungan dan pengaruh terhadap loyalitas nasabah menggunakan intenet banking Bank Syariah Mandiri cabang Pontianak

Berdasarkan hasil pengolahan data di atas, secara keseluruhan dapat disimpulkan bahwa sejumlah faktor yang diuji secara parsial yang mempengaruhi e-Loyalty nasabah Bank Syariah Mandiri cabang Pontianak untuk mengunjungi dan melakukan transaksi perbankan secara online adalah adanya penerapan strategi pemasaran produk-produk Bank Syariah Mandiri secara elektronik (e-Marketing) dan upaya mengelola hubungan dengan nasabah secara elektronik ( $e$ $C R M$ ). Dimana faktor $e$-CRM memiliki pengaruh yang lebih besar dibandingkan $e$-Marketing dalam pengaruh terhadap e-Loyalty nasabah Bank Syariah Mandiri cabang Pontianak dengan kosefisen sebesar 0,209 dibandingkan faktor e-Marketing dengan kosefisien 0,110. Kemudian secara bersama-sama faktor e-Marketing dan e-CRM mempengaruhi $e$-Loyalty nasabah Bank Syariah Mandiri cabang Pontianak sebesar 40,7\%. Sedangkan selebihnya 59,3\% dipengaruhi oleh faktor lain yang tidak dibahas dalam penelitian ini.

\section{SARAN}

Dari hasil penelitian diketahui bahwa masih terdapat faktor lain yang memiliki pengaruh yang lebih besar terhadap e-Loyalty dibandingkan faktor e-Marketing dan e-CRM. Hal ini membuka peluang untuk penelitian lebih lanjut guna mengetahui faktor apa saja yang dapat mempengaruhi $e$-Loyalty secara signifikan. Meskipun demikian, penerapan $e$-Marketing dan $e$ CRM pada internet banking Bank Syariah Mandiri sudah mendapat perhatian dari nasabahnya di cabang Pontianak, hal ini bisa diperhatikan lebih guna meningkatkan minat nasabah Bank Syariah Mandiri cabang Pontianak untuk menggunakan internet banking Bank Syariah Mandiri yaitu 
BSMnet. Misalnya dengan memaksimalkan penjelasan kepada nasabah yang menggunakan jasa customer service mengenai adanya layanan internet banking yang disediakan Bank Syariah Mandiri BSMnet yang dapat memberikan pelayanan perbankan secara online dan nonstop 24 jam. Adapun saran untuk penelitian selanjutnya yang sejenis dapat melakukan pada bank-bank yang berbeda supaya dapat melakukan perbandingan. Atau dapat menggunakan faktor-faktor lain yang diduga dapat meningkatkan minat nasabah menggunakan internet banking.

\section{DAFTAR PUSTAKA}

[1] Fauzan, H. M., Siagian, M. H. B., Siagian, Kamus Hukum dan Yurisprudensi, Kencana, Jakarta.

[2] Shafiee, M. M., Haghighizade, R., Rahimzadeh, S., 2016, A Comparative Investigation of the Impact of e-Marketing Competitive Strategies on e-Loyalty with Focusing on Porter's Model. In e-Commerce in Developing Countries: with focus on e-Tourism (ECDC), 2016 10th International Conference on. IEEE, Isfahan, 15-16 April 2016.

[3] Budiardjo, E. K., Aprillovi, D., 2009, Mobile Banking: A Customer Relationship Management (CRM) Channel. In Seminar Nasional Informatika (SEMNASIF), Yogyakarta, 23 Mei 2009.

[4] Prasetya, F. N., So, I. G., 2014, Pengaruh E-Marketing dan E-Crm Terhadap E-Loyalty Website Usaha Komunikasi Pemasaran. Binus Business Review, Vol. 5, No. 1, Hal 8-17.

[5] Kotler, P., Keller, K. L., 2008, Manajemen pemasaran. (Jilid-12).Indeks, Jakarta.

[6] Selim, H. M., 2011 Content Evaluation Criteria for General Website: Analysis and Comparison. UAE University Working Paper Series, Vol. 2, No. 3, Hal 12 - 28.

[7] Turban, E., Lee, J. K., King, D., McKay, J., Marshall, P., 2008, Electronic Commerce: A Managerial Perspective. (5 ${ }^{\text {th }}$ edition), Pearson Education, New Jersey.

[8] Chaffey, D., 2009, E-Business and e-Commerce Management. (4 ${ }^{\text {th }}$ edition), Prentice Hall, New Jersey

[9] Jih, W, -J., Lee, S. -F., 2010, Effect of E-CRM Value Perceptions on Website Loyalty: An Empirical Investigation from Customer Perspective, International Journal of E-Business Research, Vol. 6, No. 3.

[10] Yusuf. O., 2014, https://kominfo.go.id/content/detail/4286/pengguna-internet-indonesianomor-enam-dunia/0/sorotan_media

[11] Hamid, N. R. A., Cheng, A. Y., Akhir, R. M., 2011, Dimension of E-CRM: an empirical study on Hotles' web sites. Journal of Southeast Asian Research, Vol. 2011, Hal 2-12.

[12] Ghane, S., Fathian, M., Gholamian, M. R., 2011, Full Relationship among e-Satisfaction, e-Trust, e- Service Quality, and e-Loyalty: The Case of Iran Intenet Banking. Journal of Theoritical and Applied Information Technology, Vol. 33, No. 1, Hal 1 -6.

[13] Hur, Y., Ko, Y, J., Valacich, J., 2011, A Structural Model of the Relationship between Sport Website Quality, e-Satisfaction, and e-Loyalty. Journal of Sport Management, Vol. 25, No. 5, Hal 458-473.

[14] Sugiyono, (2008, Metode Penelitian Bisnis: Pendeketan Kuantitatif, Kualitatif, dan R\&D, Alfabeta, Bandung.

[15] Myers, R. H., 1990, Classical and Modern Regression with Applications, PWS and Kent Publishing Company, Boston. 
Citec Journal, Vol. 4, No. 4, Agustus 2017 - Oktober 2017

ISSN: 2354-5771

[16] Hasan, 2013, Perancangan Aplikasi Customer Relationship Management Berbasis Web pada PT. Bank Internasional Indonesia cabang Pontianak. Jurnal Sisfotenika, Vol. 3, No.2, Hal 126-135. 